\title{
Medication adherence among ambulatory patients with type 2 diabetes in a tertiary healthcare setting in Southwestern Nigeria
}

\author{
Rasaq ADISA, Titilayo O. FAKEYE, Adesoji FASANMADE.
} Received (first version): 24-Nov-2010

Accepted: 3-Apr-2011

\begin{abstract}
${ }^{\star}$
Objective: To assess adherence to medication among ambulatory patients with type 2 diabetes, ascertain the level of glycemic control, and evaluate patients' opinions on probable reasons for nonadherence with a view to identify areas of intervention to improve adherence.

Methods: A prospective cross-sectional study was carried out at a 900-bed tertiary teaching hospital in Ibadan, Southwestern Nigeria between June and August, 2009. Out of 140 consented patients, 114 $(81.4 \%)$ properly responded to the validated and pre-tested data collection tool and these were subsequently considered for analysis. Descriptive statistics were used to summarize the data. Means and proportions were compared using student t-test and chi-square or Kruskal-Wallis test as appropriate, with $p<0.05$ considered statistical significant
\end{abstract}

Results: Approximately sixty percent of the patients were adjudged adherent with prescribed medication. Out of $58.8 \%$ of the cohort who gave their recent fasting plasma glucose (FPG) values, $59.7 \%$ had FPG above $110 \mathrm{mg} / \mathrm{dL}$. The mean FPG for patients was $139.05(\mathrm{SD}=70.5) \mathrm{mg} / \mathrm{dL}$, males and females significantly differed in their mean FPG, $146.55(\mathrm{SD}=85.0) \mathrm{mg} / \mathrm{dL}$ versus 133.33 $(S D=57.6) \mathrm{mg} / \mathrm{dL}$ respectively $(p=0.032)$. Also, the mean FPG values for adherent patients, 137.09 $(\mathrm{SD}=59.3) \mathrm{mg} / \mathrm{dL}$ was lower than their non-adherent counterparts, $143.92(\mathrm{SD}=87.6) \mathrm{mg} / \mathrm{dL}$, but the difference was not statistically significant $(p=0.095)$. Financial constraint $(34.4 \%)$ was the major barrier to optimal adherence with medication. A significant association exist between genders and opinions on physician's mode of approach during patientphysician interaction as a contributory factor for non-adherence $(p=0.038)$.

Conclusion: Medication adherence of ambulatory type 2 diabetes patients is considerable. However, the relatively high level of adherence did not appear to have significantly impacted on patients' glycemic status due to a substantial number who had plasma glucose above the recommended targets. Multiple

*Rasaq ADISA. B.Pharm, M.Pharm. Lecturer 1. Department of Clinical Pharmacy \&Pharmacy Administration, Faculty of Pharmacy, University of Ibadan (Nigeria).

Titilayo O. FAKEYE. B.Pharm, M.Sc, PhD. Senior Lecturer. Department of Clinical Pharmacy \&Pharmacy Administration, Faculty of Pharmacy, University of Ibadan (Nigeria).

Adesoji FASANMADE. MBBS, FWACP. Consultant endocrinologist. Department of Medicine, Endocrinology unit, College of Medicine, University of Ibadan, (Nigeria). methods may be required to detect patient who report adherence but who may in fact be nonadherent. Also, adherence to other aspects of diabetes management plan needs to be encouraged in order to accomplish optimal glycemic control. Initiatives targeting patient-specific intervention to improve medication adherence should be considered.

Keywords: Medication adherence. Diabetes Mellitus. Nigeria.

\section{ADHERENCIA A LA MEDICACIÓN ENTRE PACIENTES CON DIABETES TIPO 2 EN \\ ESTABLECIMIENTOS SANITARIOS TERCIARIOS EN EL SUROESTE DE NIGERIA}

\section{RESUMEN}

Objetivo: Evaluar la adherencia a la medicación entre pacientes ambulatorios con diabetes tipo 2 , determinar el nivel de control glucémico, y evaluar las opiniones de los pacientes sobre las probables razones de la no adherencia con vista a identificar áreas de intervención en la mejora del cumplimiento.

Métodos: Se realizó un estudio prospectivo transversal en un hospital universitario terciario de 900 camas en Ibadan, Suroeste de Nigeria, entre junio y agosto de 2009. De los 140 pacientes que consintieron, $114(81,4 \%)$ respondieron correctamente al instrumento validado y pre-testado de recogida de datos y fueron consiguientemente analizados. Se usó estadística descriptiva para resumir los datos. Las medias y proporciones se compararon usando t de Student y chi cuadrado o test de Kruskal-Wallis, con $p<0,05$ como significación estadística.

Resultados: Aproximadamente el 60\% de los pacientes fueron considerados adherentes con la medicación prescrita. Del 58,8\% de la cohorte que dio sus valores recientes de glucemia en ajuno (GA), el 59,7\% tenía la GA por encima de 110 $\mathrm{mg} / \mathrm{dL}$. La media de GA fue de 139,05 (DE=85,0) $\mathrm{mg} / \mathrm{dL}$; hombres y mujeres difirieron significativamente en las medias: 146.55 $(\mathrm{DE}=85,0) \mathrm{mg} / \mathrm{dL}$ versus $133,33(\mathrm{DE}=57,6) \mathrm{mg} / \mathrm{dL}$ respectivamente $(\mathrm{p}=0,032)$. También, las medias de GA en pacientes adherentes, 137,09 (DE=59.3) $\mathrm{mg} / \mathrm{dL}$ fue menor que en su contraparte no adherente, 143,92 $(\mathrm{DE}=87,6) \mathrm{mg} / \mathrm{dL}$, pero la diferencia no fue significativa $(\mathrm{p}=0,095)$. Las restricciones financieras $(34,4 \%)$ fueron la principal barrera para una buena adherencia a la medicación. 
Existe una asociación significativa entre géneros y opiniones de la forma del médico de abordar la interacción paciente-médico como un factor contributivo de no adherencia $(\mathrm{p}=0,038)$.

Conclusión: La adherencia a la medicación en los pacientes ambulatorios con diabetes tipo 2 es considerable. Sin embargo, el relativamente alto nivel de adherencia no pareció tener impacto significativo en el estado glucémico debido al número importante que tenia glucemias por encima de las recomendadas. Pueden necesitarse múltiples métodos para detectar pacientes que reportan ser adherentes pero que de hecho no lo son. Asimismo, la adherencia a otros aspectos del manejo de la diabetes deben ser promovidos para conseguir un óptimo control glucémico. Deberían ser consideradas iniciativas dirigidas a cada paciente para mejorar la adherencia a la medicación.

Palabras clave: Adherencia a la medicación. Diabetes mellitus. Nigeria.

\section{INTRODUCTION}

Medication non-adherence is defined as patient's failure to engage in a therapeutic regimen because of deficit in one or more of these pre-requisites: comprehension of the regimen, regard for the value of medical advice, or skills required for selfmanagement. In both developed and developing countries, non-adherence to medication remains a significant concern for physicians, providers, and patients partly because of its adverse consequences on therapeutic outcomes. ${ }^{1,2}$ It is a significant but often unrecognized risk factor universal to all patients populations most especially those with chronic illness that involves complex and long term medical regimen., ${ }^{2,3}$ In addition to inadequate disease control, poor adherence to diabetes treatment recommendations (diet, medications and exercise) would also decrease treatment effectiveness ${ }^{4,5}$ with subsequent manifestation of micro- and macro-vascular complications of diabetes and increased health care costs. ${ }^{6,7}$ Non-adherence rates are relatively high across disease states, treatment regimens, and age groups. The drop in adherence is noted to be most dramatic after the first six months of therapy among patients with chronic conditions such as diabetes mellitus. ${ }^{8,9}$ A systematic review of studies on adherence to medication among diabetes patients showed that average adherence to oral antidiabetes medications ranges from $36 \%$ to $93 \%{ }^{10}$, while adherence to other treatment recommendations especially dietary adherence among these patients remains poor. ${ }^{11-13}$ Diabetes mellitus is a chronic metabolic disorder requiring long term and sometimes complex treatment regimen. The changes in lifestyle as a result of urbanization and westernization might have contributed to a progressive increase in the incidence of type 2 diabetes worldwide. ${ }^{14-18}$ Optimal management of diabetes involve patients taken prescribed medications (insulin or oral drugs) regularly and appropriately on a daily basis with minimal or no supervision. In addition, patients are required to adhere strictly to recommended diet and exercise plans, as well as measuring and keeping a diary/record of their own blood glucose measurements. ${ }^{19-23}$ Accomplishment of the diabetes treatment plans by patients are essential in order to ensure normal or near normal fasting and postprandial blood glucose levels necessary for adequate control of diabetes, and subsequent reduction in mortality and reduced risk of complications in patients with type 2 diabetes. ${ }^{24,25}$ However, the need to make patients adequately committed to take their hypoglycemic medications regularly and appropriately, as well as adjusting their long-standing lifestyles in order to achieve optimal glycemic outcome is among the most common challenges encountered by physicians and other healthcare providers involved in diabetes care. $^{22,26}$

Adherence research and education have focused on understanding and addressing the contextual factors that contributes to medication nonadherence. ${ }^{27}$ Demographic characteristics may help to identify patients who are at risk for nonadherence. ${ }^{28}$ Similarly, medication may contribute to non-adherence secondary to side effects and cost, while poor patient-healthcare provider relationships may also be a major determinant of nonadherence. ${ }^{28}$ Nevertheless, literature on adherence to treatment for chronic condition such as diabetes call for more empirical research to assess patients' adherence to medication, identify the reasons for non-adherence, and emphasized the necessity of this information for the development of specific intervention that focus on these reasons to improve adherence. ${ }^{29,30,31}$ In resource-limited countries like Nigeria, the preponderance of economic instability, low literacy level, and restricted access to health care facilities might have led to the increase incidence of medication non-adherence. To the best of our knowledge, evidence-based research that evaluate medication adherence among patients with type 2 diabetes in Nigeria is scanty. Thus, the need for this study which aimed to assess medication adherence of ambulatory type 2 diabetes patients who attend an endocrinology clinic of a 900-bed tertiary teaching hospital in Ibadan, southwestern Nigeria, ascertain the level of glycemic control among these patients, and evaluate their opinions on the probable reasons for medication nonadherence. Association between sociodemographic characteristics and adherence status, as well as relationship between demographic variables and patients' opinions on the likely reasons for non-adherence were investigated. The differences in mean fasting plasma glucose values between and among different categories of patients were also compared.

\section{METHODS}

A prospective cross-sectional study was conducted at the endocrinology outpatient clinic of University College Hospital ( $\mathrm{UCH}$ ), Ibadan between June and August, 2009. UCH is a 900-bed tertiary healthcare facility located in Ibadan and affiliated with the 
University of Ibadan in southwestern, Nigeria. The hospital provides treatment for different categories of ambulatory and institutionalized patients within and outside the region and is a major site for undergraduate and post-graduate residency training. Ethical clearance and approval of the study protocols was granted by the joint University of Ibadan/UCH Research and Ethics Committee. The data available from the medical record unit of the hospital showed that an average of between 25 and 30 ambulatory diabetes patients are attended to by the resident and consultant endocrinologists on a regular basis per diabetes clinic day (Mondays).

Adult type 2 diabetes patients who were either diagnosed in the endocrinology clinic of the hospital or referred to the clinic from either private and other public hospitals in Nigeria, who must also have been on hypoglycemic medication(s) for more than three months to ensure familiarization with diabetes and the prescribed hypoglycemic medications were considered for inclusion in the study. The objectives of the study were explained to individual patient. Only those who were interested and who gave their voluntary informed consent to partake in the study were enrolled. Patients were assured of their anonymity and confidentiality of responses. Excluded were all type 1 diabetes patients, and patients who were mentally incompetent or who declined participation in the study. Based on the estimated population of 220 patients for the study period, at $95 \%$ confidence level and $5 \%$ confidence interval, a target sample size of 140 was calculated using a sample size calculator (www.surveysystem.com/sscalc.html). ${ }^{32}$ An average of between 18 and 20 patients fulfill the study inclusion criteria per clinic days, given a total of 152 eligible patients who were approached within study period. Of these, 140 consented to participate, and these were patients who were administered the research instrument. The instrument for data collection was a structured questionnaire consisting of dichotomous (Yes/No options), 5-point Likert (ordinal) scale, open-ended, and closed-ended questions. The instrument was assessed for clarity and comprehensiveness of content by giving copies to two physicians who were experts in the field of endocrinology and two pharmacists who were experienced scholars in diabetes mellitus. To ascertain the appropriateness of the study design, pre-testing of sampling and recruitment procedures was done among fifteen randomly selected, recently diagnosed type 2 diabetes patients or those who had been on hypoglycemic medications for less than 3 months. Based on the feedback from the pretest and validity assessment, study duration of 2 months was considered appropriate for the study, since two months was found to be the minimum clinic appointment date for diabetes patients except for those who have urgent reason(s) for whom an appointment of less than a month may be given. The 8 week period was also chosen to further ensure that no patient was repeated within the study period. Some questions were also reworded to eliminate ambiguous phrasing, in particular, the Likert type questions that were initially constructed in table format were changed to the text format for better understanding by patients. The questionnaire was divided into four sections; the first section obtained information on socio-demographic data including age, sex, occupation, educational and marital status, as well as diabetes-specific parameter mainly record of most recent fasting plasma glucose value which was confirmed or cross-checked from the blood glucose result brought to the clinic by patients. The FPG and weight are routine measurements in the endocrinology clinic of the hospital which need to be done by every diabetes patients prior to physician's visit on the clinic day. The blood glucose meter (Accu-chek ${ }^{\circledR}$ Active) was the most commonly use device in the clinic for routine blood glucose measurements. In this study, adequate/good glycemic control was defined as FPG $\leq 110 \mathrm{mg} / \mathrm{dL}$ and poor glycemic control as FPG $>110 \mathrm{mg} / \mathrm{dL}$. This classification was based on the United Kingdom Prospective Diabetes Study Group definition of intensive control for diabetes patients (as fasting plasma glucose (FPG) of less than $108 \mathrm{mg} / \mathrm{dL}$ ). ${ }^{33,34}$ The second section clarified information on duration of diagnosis as type 2 diabetes, profile of prescribed antidiabetes medications and non-drug treatment recommendations, as well as opinions on duration of antidiabetes medication/treatment plans. The third section contained 4-item Modified Morisky Adherence Predictor Scale (MMAPS) ${ }^{35}$, administered in a dichotomous version (Yes/No). MMAPS is part of the WHO case management adherence guideline (CMAG) assessment tools ${ }^{36}$, and it is a validated scale mostly used to classify patients on medication as either high or low on motivation and knowledge domain, thus a commonly used self-report method to assess patients' adherence to existing therapy. MMAPS is 4 -item questions which assess unintentional (question 1 and 2) and intentional (question 3 and 4) non-adherence behaviours. Adherence in this study was defined as no positive response (or a total score of zero) to the 4-item question on the MMAPS. Binary variables using categorization of $<1$ versus $\geq 1$ for classification of patients into adherent and non-adherent status respectively, were based on the distribution of data following an extensive review of the literature. ${ }^{35,37}$ The fourth section contained 5-point Likert scale (ranging from strongly agree -assigned a value of 5 to strongly disagree assigned a value of 1) to evaluate patients' opinions on some of the likely reasons for non-adherence in relation to their own medication-taking behaviours or adherence. The probable reasons for medication non-adherence were compiled following an extensive review of literature $e^{1,30,37-41}$, and contained some of the intentional and unintentional barriers or reasons for non-adherence among patients on chronic or long term medication/treatment plans. The questionnaires, which took between 20 and 25 minutes to be completed, were administered to consented type 2 diabetes patients by the principal investigator on every diabetes clinic days. Only 7 (6.1\%) patients who did not understand English language were assisted by the principal investigator and their responses were later translated and backtranslated to maintain response consistency. Out of the one hundred and forty copies of questionnaire administered to patients within the study period, 114 
$(81.4 \%)$ were considered for analysis. The remainder, $26(18.6 \%)$ were not used for analysis because of ambiguous responses or incomplete demographic data.

Data were sorted, coded and entered into Predictive Analytics Software (PASW) (formerly SPSS) window version 17.0 for management and analysis. Descriptive statistics including frequency, mean, range, and standard deviation were used to summarize patients' baseline socio-demographic data and evaluate distribution of responses. Chisquare was used to investigate association between socio-demographic characteristics and medication adherence status, while Kruskal-Wallis test (a nonparametric form of ANOVA) was used to evaluate association between socio-demographic variables and patients' opinions on the probable reasons for medication non-adherence. Student t-test was used to compare the difference in mean FPG between adherent and non-adherent patients, as well as between genders. One-way Analysis of Variance (ANOVA) was used to compare the differences in mean FPG values among patients of different sociodemographic status. The priori level for statistical significance was set at $p<0.05$.

\section{RESULTS}

The response rate from this study was $81.4 \%$. Sixtythree $(55.3 \%)$ were females and $51(44.7 \%)$ were males. The mean age for the studied population was $61.32(S D=12.40)$ years (range 32 to 83 years). Males have a mean age of $60.51(S D=11.33)$ years, versus females mean age of $61.99(S D=13.28)$ years (Student-t test $(\mathrm{t})$ value $=0.627 ; \mathrm{p}=0.181$ ). Thirty $(26.3 \%)$ were retirees from private and public establishments, $29(25.4 \%)$ were traders, and 49 $(43.0 \%)$ had post-secondary or tertiary education. The details of the socio-demographic characteristics of patients were given in Table 1. Overall, patients had been diagnosed with diabetes for $8.4(S D=7.9)$ years. Eighty-one $(71.1 \%)$ had been diagnosed for between 1 and 10 years, $13(11.4 \%)$ diagnosed 11 to 20 years, $7(6.1 \%)$ for $21-30$ years, $3(2.6 \%)$ patients diagnosed between 3 and 6 months, and 3 $(2.6 \%)$ had type 2 diabetes for over 30 years. Seven $(6.1 \%)$ could not give any response. Male and female patients significantly differed in mean year/duration of diagnosis, $10.10(S D=8.80)$ years versus $7.18(S D=6.79)$ years $(t=1.936 ; p=0.031)$.

The profile of prescribed antidiabetes medications among the patients indicated that a combination of sulfonylurea mostly glibenclamide, and metformin as co-administered products $42(36.8 \%)$, was the most commonly prescribed. Metformin alone was used by $19(16.7 \%)$; insulin alone, $15(13.2 \%)$; and glibenclamide alone, 8 (7.0\%). Combination of metformin and insulin were used by 7 (6.1\%), other combination of oral agents by $6(5.3 \%)$, combination of glibenclamide, metformin and insulin, 2 (1.8\%); while $1(0.9 \%)$ was on pioglitazone. Fourteen $(12.3 \%)$ could not identify the antidiabetes medicines they were taking. The non-medicine treatment modalities practiced by patients included dietary adjustments, 59 (32.6\%), exercise 52 $(28.7 \%)$, self-monitoring of blood glucose (SMBG),
$46(25.4 \%)$; and weight reduction, 24 (13.3\%). In most cases, patients were on combinations of these non-drug recommendations.

\begin{tabular}{|c|c|c|}
\hline Variables & Frequency & Percent \\
\hline \multicolumn{3}{|l|}{ Age (years) } \\
\hline $30-40$ & 8 & 7.0 \\
\hline $41-50$ & 17 & 14.9 \\
\hline $51-60$ & 31 & 27.2 \\
\hline $61-70$ & 28 & 24.6 \\
\hline Above 70 & 30 & 26.3 \\
\hline \multicolumn{3}{|l|}{ Sex } \\
\hline Male & 51 & 44.7 \\
\hline Female & 63 & 55.3 \\
\hline \multicolumn{3}{|l|}{ Occupation } \\
\hline Artisans & 6 & 5.3 \\
\hline Unemployed & 10 & 8.8 \\
\hline Civil servant & 11 & 9.6 \\
\hline Professionals & 28 & 24.6 \\
\hline Trading & 29 & 25.4 \\
\hline Retiree & 30 & 26.3 \\
\hline \multicolumn{3}{|l|}{ Educational qualification } \\
\hline No formal education & 11 & 9.6 \\
\hline Primary & 22 & 19.3 \\
\hline Secondary & 32 & 28.1 \\
\hline Tertiary & 49 & 43.0 \\
\hline \multicolumn{3}{|l|}{ Marital status } \\
\hline Single & 5 & 4.4 \\
\hline Married & 89 & 78.1 \\
\hline Widowed & 17 & 14.9 \\
\hline Divorced & 3 & 2.6 \\
\hline
\end{tabular}

Sixty-seven $(58.8 \%)$ patients knew the most recent value of their fasting plasma glucose which was either confirmed from the result of routine blood glucose measurements done in the hospital prior to physician's visit on the clinic day, 60 (89.6\%); or the individual self-monitored blood glucose chart brought to the clinic by patients, 7 (10.4\%). Fourtyseven $(41.2 \%)$ could not give their blood glucose value. Of the cohort who gave their FPG values, 3 $(4.5 \%)$ had fasting plasma glucose between 45 $70 \mathrm{mg} / \mathrm{dL}, 24(35.8 \%)$ had between $70-110 \mathrm{mg} / \mathrm{dL}$, $17(25.4 \%)$ had FPG between $111-130 \mathrm{mg} / \mathrm{dL}$, and $23(34.3 \%)$ had FPG $>130 \mathrm{mg} / \mathrm{dL}$. Thus, only 27 $(40.3 \%)$ of the patients had FPG below $110 \mathrm{mg} / \mathrm{dL}$ suggestive of adequate glycemic control, while 40 $(59.7 \%)$ had FPG above $110 \mathrm{mg} / \mathrm{dL}$ indicative of poor glycemic control. The mean FPG for the cohort was $139.05(\mathrm{SD}=70.46) \mathrm{mg} / \mathrm{dL}$. Male and female patients significantly differed in their mean FPG, that is, $146.55(\mathrm{SD}=84.96) \mathrm{mg} / \mathrm{dL}$ versus 133.33 $(\mathrm{SD}=57.58) \mathrm{mg} / \mathrm{dL}$, respectively $(\mathrm{t}=0.759 ; \mathrm{p}=0.032)$. However, there were no statistical significant differences in the mean FPG among patients of different occupations, marital, and educational status $(p>0.05)$. The assessment of the patients' responses to the 4-item modified Morisky adherence predictor scale showed that $60.2 \%$ of the patients were adherent with prescribed medication, while $39.8 \%$ were adjudged non-adherent (Table 2 ). Only the marital status had statistically significant influence on patients' extent of adherence to medication (Chi-square $=7.844, p=0.049$ ). Patients who are widowed $(80.0 \%)$ seemed to adhere better than the married $(60.0 \%)$, singles $(40.0 \%)$ and the divorced $(0.0 \%)$. The mean FPG for adherent patients, $137.09(\mathrm{SD}=59.27) \mathrm{mg} / \mathrm{dL}$ was lower than those of their non-adherent counterparts, 143.92 
$(\mathrm{SD}=87.56) \mathrm{mg} / \mathrm{dL}$, but the difference was not statistically significant $(t=-0.373, \quad p=0.095)$. Evaluation of patients' opinions on some of the likely reasons for non-adherence indicated that, 33 (34.4\%) strongly agreed that high costs of medication was the most frequent reason preventing optimal adherence to prescribed medication(s), while $23(29.9 \%)$ agreed that complexity of dosage regimen was also a paramount reason for medication non-adherence. Twenty (23.3\%) and $16(19.5 \%)$ agreed that physician's and pharmacist's mode of approach during consultation and dispensing respectively could be a contributory factor to lack of optimal commitment to medication-taking as prescribed. Forgetfulness, $23(28.8 \%)$, was also agreed to as a reason for medication non-adherence. The details of patients' opinions on other reasons for medication non-adherence are as shown in Table 3. There was a significant association between patients' occupational status and opinions on costs of medication as reason preventing optimal adherence to medication ( $p=0.000$; Table 4). Also, there exists a statistically significant association between genders and opinions on physician's mode of approach during consultation as a contributory factor for medication non-adherence (Kruskal-Wallis value $=4.314 ; \mathrm{p}=0.038$ ). Males were those in majority (mean rank=49.23) who were strongly in agreement with the fact that the mode/style of approach during patient-physician interaction may be a contributing reason to medication nonadherence, when compared to the female patients (mean rank=38.52).

In addition, patients' knowledge on duration of antidiabetes medication/treatment plan indicated that, only $30(26.3 \%)$ were aware that the medications plans for diabetes need to be continued throughout their lifetime. Forty-five (39.5\%) patients were not aware of how long they were going to take their antidiabetes medications, $16(14.0 \%)$ were of the opinion that medications should only be continued till next physician's appointment, 14 $(12.3 \%)$ believed that antidiabetes medications should be taken till the experienced symptoms resolve, and $9(7.9 \%)$ could not give any response. A significant association exist between patients' opinions on duration of antidiabetes medication plan and keeping a record/chart of blood glucose values (chi-square=17.92, $p=0.001)$. Majority, $(76.7 \%)$ of the patients who were aware that antidiabetes medication(s) need to be taken throughout lifetime were also conversant with the importance of keeping a record of blood glucose and thus knew their recent blood glucose values. Patients who were unaware of duration of antidiabetes regimen constituted the larger proportion (100.0\%), of those who could not give their recent glycemic value.

\begin{tabular}{|c|c|c|}
\hline Question & Numbe & \\
\hline Response (score coding) & Yes (1) & N0 (0) \\
\hline 1. Do you ever forget to take your Medication(s)? & $23(21.3)$ & $85(78.7)$ \\
\hline 2. Do you sometimes not being careful in taking your medication (s)? & $12(11.1)$ & $96(88.9)$ \\
\hline 3. When you feel better, do you sometimes stop taking your medication(s)? & $11(10.2)$ & $97(89.8)$ \\
\hline 4. Sometimes if you feel worse when you take your medication(s), do you & $12(11.1)$ & 96 (88.9) \\
\hline Distribution of scores & \multicolumn{2}{|c|}{ Total (\%) } \\
\hline 0 & \multicolumn{2}{|c|}{$65(60.2)$} \\
\hline 1 & \multicolumn{2}{|c|}{$30(27.8)$} \\
\hline 2 & \multicolumn{2}{|c|}{$7(6.5 \%)$} \\
\hline 3 & \multirow{2}{*}{\multicolumn{2}{|c|}{$4(3.7 \%)$}} \\
\hline 4 & & \\
\hline Cut-off & Number $(\%$ & Category \\
\hline$<1$ & $65(60.2)$ & Adherent \\
\hline$\geq 1$ & $43(39.8)$ & Non adherent \\
\hline
\end{tabular}

\begin{tabular}{|c|c|c|c|c|c|}
\hline $\mathrm{N}(\%)$ & SA & A & AR & $\mathrm{D}$ & SD \\
\hline 1. Costs of medication too expensive $(n=96)$ & $33(34.4)$ & $29(30.2)$ & $9(9.4)$ & $21(21.9)$ & $4(4.2)$ \\
\hline 2. Complexity of dosage regimen $(n=77)$ & $8(10.4)$ & $23(29.9)$ & $7(9.1)$ & $29(37.7)$ & $10(13.0)$ \\
\hline $\begin{array}{l}\text { 3. Physician's mode of approach during consultation } \\
(n=86)\end{array}$ & $7(8.1)$ & $20(23.3)$ & $7(8.1)$ & $35(40.7)$ & $17(19.8)$ \\
\hline $\begin{array}{l}\text { 4. Pharmacist's mode of approach during dispensing } \\
(\mathrm{n}=82)\end{array}$ & $8(9.8)$ & $16(19.5)$ & $7(8.5)$ & $37(45.1)$ & $14(17.1)$ \\
\hline 5. Lack of trust in the efficacy of medication $(n=77)$ & $8(10.4)$ & $11(14.3)$ & $9(11.7)$ & $35(45.5)$ & $14(18.2)$ \\
\hline 6. Forgetfulness $(n=80)$ & $7(8.8)$ & $23(28.8)$ & $13(16.3)$ & $27(33.8)$ & $10(12.5)$ \\
\hline 7. Omission of doses $(n=79)$ & $9(11.4)$ & $16(20.3)$ & $8(10.1)$ & $36(45.6)$ & $10(12.7)$ \\
\hline 8. Instruction for administration not clear $(n=77)$ & $4(5.2)$ & $14(18.2)$ & $14(18.2)$ & $42(54.5)$ & $3(3.9)$ \\
\hline
\end{tabular}




\begin{tabular}{|c|c|c|c|}
\hline Variables & Number & Mean rank & $\begin{array}{l}\text { Kruskal-Wallis } \\
\text { ( } p \text {-value) }\end{array}$ \\
\hline $\begin{array}{l}\text { Age (year) } \\
30-40 \\
41-50 \\
51-60 \\
61-70 \\
\text { Above } 70\end{array}$ & $\begin{array}{l}7 \\
16 \\
27 \\
25 \\
21\end{array}$ & $\begin{array}{l}46.21 \\
50.16 \\
55.13 \\
38.60 \\
51.26 \\
\end{array}$ & 0.246 \\
\hline $\begin{array}{l}\text { Sex } \\
\text { Males } \\
\text { Females }\end{array}$ & $\begin{array}{l}43 \\
53 \\
\end{array}$ & $\begin{array}{l}45.63 \\
50.83 \\
\end{array}$ & 0.343 \\
\hline $\begin{array}{l}\text { Occupation } \\
\text { Artisan } \\
\text { Civil servant } \\
\text { Unemployed } \\
\text { Retiree } \\
\text { Trading } \\
\text { Professional }\end{array}$ & $\begin{array}{c}4 \\
8 \\
9 \\
23 \\
26 \\
26\end{array}$ & $\begin{array}{l}24.75 \\
79.81 \\
45.56 \\
34.67 \\
45.13 \\
59.13\end{array}$ & $0.000^{*}$ \\
\hline $\begin{array}{l}\text { Educational qualification } \\
\text { No formal education } \\
\text { Primary } \\
\text { Secondary } \\
\text { Tertiary }\end{array}$ & $\begin{array}{c}9 \\
19 \\
23 \\
45\end{array}$ & $\begin{array}{l}54.17 \\
54.97 \\
40.30 \\
48.82 \\
\end{array}$ & 0.297 \\
\hline $\begin{array}{l}\text { Marital status } \\
\text { Single } \\
\text { Married } \\
\text { Widowed } \\
\text { Divorced }\end{array}$ & $\begin{array}{c}4 \\
78 \\
11 \\
3\end{array}$ & $\begin{array}{c}29.50 \\
49.76 \\
55.05 \\
17.0\end{array}$ & 0.071 \\
\hline
\end{tabular}

\section{DISCUSSION}

Despite evidence from multiple intervention studies that better glycemic control can improve diabetes clinical, economic and humanistic outcomes, many patients failed to achieve and maintain adequate glycemic control. This may be due, in part, to patients' poor adherence to various aspects of prescribed antidiabetes treatment regimen. ${ }^{42-44}$ In the present study, there were more female than male patients probably justifying the findings from previous studies in southwestern Nigeria that obesity and insulin resistance which are risk factors for type 2 diabetes mellitus are found to be more common among women. ${ }^{45,46}$ Approximately sixty percent of patients were adjudged adherent with their medication(s), while more than one third of patients were classified as non-adherent. The adherence rate of sixty-percent from this study was within the range of adherence to medication(s) among diabetes patients as reported in the previous studies. ${ }^{10,47}$ However, the relatively high level of adherence to medication among these patients did not appear to translate directly to the accomplishment of target glycemic goals for diabetes patients. About sixty percent of patients who gave their recent glycemic value had a FPG above the recommended target indicative of adequate glycemic control. ${ }^{33,34}$ This may probably suggest in part the need to look at other aspects of diabetes management plans especially dietary adherence, blood pressure and lipid control, weight reduction, and exercise program. Studies have shown that adherence to all aspect of diabetes management plan is essential in order to accomplish an optimal glycemic control. ${ }^{48-51}$
Although, the Morisky adherence predictor scale has been found to be a reliable tool to classify patients as either high or low on motivation and knowledge domain, thus may provide a reasonably accurate estimate of medication adherence. Nonetheless, multiple methods may be required to detect those who report adherence but who may in fact be non-adherent. ${ }^{37,52-55}$ It is worthy to mention that adherent patients had lower and thus better glycemic control than their non-adherent counterparts suggesting that if patients are more committed to medication-taking as prescribed, glycemic outcome will improve. Healthcare providers need to continually reinforce and emphasize the important of medication adherence at every contact with patients.

A substantial proportion of patients who could not give their recent blood glucose value is probably an indication of low potential for keeping record of blood glucose measurement among diabetes patients generally. By keeping a diary/record of their own blood glucose measurements and monitoring the effect of food and exercise on their glycemic status, patients will be able to make appropriate lifestyle modifications in order to achieve better control of diabetes ${ }^{22,23}$, monitor response to therapy, and more importantly, enable the attending physician to develop a rational treatment plans with the patients. Thus, keeping a record of blood glucose value is a critical step towards diabetes self-management efforts, and a gesture that need to be encouraged among diabetes patients generally. Interestingly, patients who kept their plasma glucose values were mostly those who were aware of the lifelong nature of diabetes and antidiabetes 
medication plan(s). This may probably imply that having a basic knowledge of a medical illness could impact positively on patient's self management efforts. Although, this gesture may perhaps be in contrary to the belief that keeping patients aware of the full course of treatment plan(s) for chronic illness might generate fear and may make many of them to seek for alternative care. Notwithstanding, patients need to be adequately informed of the longterm diabetes care plans, so as to enable them to be physically, mentally, and economically prepared for the challenges ahead. This becomes imperative for improved medication adherence and better glycemic outcome.

The high costs of medication agreed to by majority of the patients as the most important reason preventing optimal adherence had been supported by previous studies where financial constraint was identified as the major hindrance to medication adherence among type 2 diabetes populations. ${ }^{30,46,56,57}$ Increased generic prescribing rather than use of brand names without compromising efficacy or treatment standard should be encouraged to reduce costs of medication and foster patients' compliance. It is of note that, patients who were civil servants were those in majority who strongly believed that the high costs of prescribed antidiabetes medications could be an important barrier to optimal adherence, compared with patients who were artisans. Botelho \& Dudrak ${ }^{58}$ have shown that socio-economic factors play a vital role on adherence as patients who live on a fixed income would most likely be able to predict how much he is expending on medications on a monthly basis. This class of patients would probably feel the impact of medication costs more than patients who may be on variable daily or monthly income. Patients' recognition of healthcare provider's mode of approach during patient-healthcare provider's interaction as part of the reasons contributing to medication non-adherence is a call for concern among healthcare providers generally, and an aspect that need to be critically looked at, so as to identify what should be done to promote better relationships between the patients and providers. Roter et al. ${ }^{59}$ and Sleath et al. ${ }^{60}$ identified the relationship between the patient and healthcare provider as a substantial predictor of adherence such that if patient perceives the provider as caring and concerned, adherence is likely to be higher. Thus, health care providers should imbibe the culture of empathic response and listening when interacting with patients. Once patients have positive experiences with, and trust the healthcare provider, they will be motivated to follow instructions given by the provider. ${ }^{61,62}$

Although, this study provides valuable information on medication adherence and management of type 2 diabetes patients in a clinical setting, there is need to consider the study findings in line with some of its limitations which includes lack of detailed information on adherence to other aspects of diabetes management plan, particularly dietary adherence, and frequency of self-monitoring of blood glucose by patients. The glycosilated hemoglobin (HbA1c) test was not routinely recommended for patients probably on account of the high cost of the test in the hospital or because it may not be part of the established guideline within the hospital. However, it might have been used as a better objective indicator of glycemic control. Fasting plasma glucose and/or 2-hour post-prandial glucose were the common blood glucose tests usually prescribed for diabetes patients, and assessment of patient's glycemic response is usually based on the value of these tests. Also, this study did not evaluate directly the influence of types of medication/regimen taken by patients on their adherence status. Nonetheless, the MMAPS and some of the probable reasons for non-adherence evaluated in this study were structured in relation to different aspects of medication-taking behaviour of patients which may affect their adherence. Future research to evaluate the direct impact of types and quantity of medication on patient's adherence may need to be considered. The 4-item modified Morisky adherence predictor scale used to assess medication adherence might be associated with some shortcomings since it is a self-report method, however, there is no gold standard method for assessing adherence. Self-report measure of adherence using a non threatening and nonjudgmental question may make patients to feel more comfortable in telling the truth about their medication adherence when compared to the supposedly objective methods such as pill count or prescription claim data. ${ }^{28,63}$

\section{CONCLUSIONS}

Overall, the findings from the present study indicated that the medication adherence of ambulatory type 2 diabetes patients in a tertiary healthcare setting in southwestern Nigeria is considerable. However, the relatively high adherence rate did not appear to have appreciably impacted on patients' glycemic value, as a sizeable number of patients had a fasting plasma glucose value above the recommended glycemic goals indicative of adequate control. Better glycemic value among adherent patients compared to their non-adherent counterparts probably corroborates the fact that taking medication appropriately as prescribed could lead to improved glycemic response. Financial constraint was the most important reason preventing optimal adherence to prescribed medication, but there is need to promote better therapeutic relationship between the patient and diabetes care provider in order to ensure optimal medication adherence. In addition, multiple methods of adherence assessment, involving semistructured clinical interview with patient or caregiver, may be required to detect patient who report adherence but who may in fact be non-adherent. Efforts should also gear towards ensuring patient's adherence to other aspects of diabetes management plan so as to optimize outcome. Initiatives targeting patient-specific intervention should be considered so as to recognize nonadherence problem(s), and identify the underlying reason(s) or cause of non-adherence among patients, with a view to provide practical and functional solution to resolve the problem(s) and 
improve adherence. The intervention should have some follow-up component in order to ensure sustained improvement in medication adherence.

\section{CONFLICT OF INTEREST}

None declared.

\section{References}

1. Harold G. Medication Non adherence: Finding solutions to a costly medical problem. Drug Benefit Trends. 2000;12(6):57-62.

2. Munger MA, VanTassel BW, LaFleur J. Medication nonadherence: An unrecognized cardiovascular Risk factor MedGenMed. 2007;9(3):58.

3. Blaskelee D. Adherence to therapy. Journal of American Medical Association HIVIAIDS 1998.

4. Schetman JM, Nadkarni MM, Voss JD. The association between diabetes metabolic control and drug adherence in an indigent population. Diabetes Care. 2002;25(6):1015-1021.

5. Krapek K, King K, Warren SS, George KG, Caputo DA, Mihelich K, Holst EM, Nichol MB, Shi SG, Livengood KB, Walden S, Lubowski TJ. Medication adherence and associated hemoglobin AIC in type 2 diabetes. Ann Pharmacother. 2004;38(9):1357-1362.

6. Sokol MC, McGuigan KA, Verbrugge RR, Epstein RS. Impact of medication adherence on hospitalization risk and healthcare cost. Med Care. 2005;43(6):521-530.

7. Lee WC, Balu S, Cobden D, Joshi AV, Pashos CL. Prevalence and economic consequences of medication adherence on diabetes: a systematic literature review. Manag Care Interface. 2006 Jul;19(7):31-41.

8. Haynes RB, McDonald HP, Garg AX.. Helping patients follow prescribed treatment: Clinical applications. JAMA. 2002;288(22):2880-2883.

9. Cramer J, Rosenheck R, Kirk G, Krol W, Krystal J; VA Naltrexone Study Group 425. Medication compliance feedback and monitoring in a clinical trial: Predictors and outcomes. Value Health. 2003;6(5):566-573.

10. Cramer JA. A systematic review of adherence with medications for diabetes. Diabetes Care. 2004;27(5):1218-1224.

11. Peyrot M, Rubin RR, Lauritzen T, Snoek FJ, Matthews DR, Skovlund SE.. Psychosocial problems and barrier to improved diabetes management:results of the Cross-National Diabetes Attitudes, Wishes and Needs (DAWN) study. Diabet Med. 2005;22(10):1379-1385.

12. Thanopoulou A, Karamanos B, Angelico F, Assaad-Khalil S, Barbato A, Del Ben M, Djordjevic P, Dimitrijevic-Sreckovic V, Gallotti C, Katsilambros N, Migdalis I, Mrabet M, Petkova M, Roussi D, Tenconi MT; Multi-Centre Study of the Mediterranean Group for the Study of Diabetes (MGSD). Nutritional habits of subjects with type 2 diabetes mellitus in the Mediteranean Basin:comparism with the non-diabetic population and the dietary recommendations. Multicentre study of the Mediterrnean Group for the study of Diabetes (MGSD). Diabetologia. 2004;47(3):367-376.

13. Glasgow RE, Hampson SE, Strycker LA, Ruggiero L. Personal-model beliefs and socio-enviromental barriers related to diabetes self-management. Diabetes Care. 1997;20(4):556-561.

14. King $\mathrm{H}$, Rewers $\mathrm{M}$. Global estimates for the prevalence of diabetes mellitus and impaired glucose tolerance in adults. WHO Ad hoc Reporting Group. Diabetes Care. 1993;16(1):157-177.

15. World Health Organization. Prevention of diabetes mellitus. Report of a WHO Study Group. WHO Technical Report series 844, Geneva WHO. 1994.

16. Amos AF, McCarty DJ, Zimmet $P$. The rising global burden of diabetes and its complication, estimates and projection to the year 2010. Diabet Med. 1997;14(Suppl 5):S1-85.

17. Unwin N, Sobugivi E, Alberto KGMM. Type 2 diabetes: the challenge of preventing a global epidemic. Diabetes International. 2001;11:4-8.

18. WHO/IDF. Screening for type 2 diabetes. Report of a World Health Organization and International Diabetes Federation Meeting. WHO/NMH/NMC/03:1. Geneva: WHO department of non communicable Disease Management. Available at http://www.who.int (Accessed on 10th May, 2009).

19. McCulloch DK. Patient information: Diabetes mellitus type 2: Alcohol, exercise, and medical care. In: Moynihan LK, Mulder JE., Holman RB eds. American Diabetes Association. 1997.

20. American Diabetes Association. Diabetes mellitus and exercise. Diabetes Care. 1997;20:1908-1912.

21. Zinman B, Ruderman N, Campaigne BN, Devlin JT, Schneider SH; American Diabetes Association. Physical activity/exercise and Diabetes. Diabetes Care. 2004;27(Suppl 1):S58-62.

22. Gray A, Raikou M, McGuire A, Fenn P, Stevens R, Cull C, Stratton I, Adler A, Holman R, Turner R. Cost effectiveness of intensive blood glucose control policy in patients wity type 2 diabetes:economic analysis alongside randomised controlled trial (UKPDS 41). United Kingdom Prospective Diabetes Study Group. BMJ. 2000;320(7246):1373-1378.

23. American Diabetes Association. Standards of medical care in diabetes 2006. Diabetes Care. 2006;29(Suppl 1):S4-42.

24. Andersson DK, Svärdsudd K.. Long-term glycemic control relates to mortality in type 2 diabetes. Diabetes Care. 1995;18(12):1534-1543.

25. Ohkubo Y, Kishikawa H, Araki E, Miyata T, Isami S, Motoyoshi S, Kojima Y, Furuyoshi N, Shichiri M. Intensive insulin therapy prevents the progression of diabetic micro-vascular complications in Japanese patients with non-insulin dependent diabetes mellitus: a randomized prospective 6 years study. Diabetes Res Clin Pract. 1995;28(2):103-117.

26. Jacques $\mathrm{CH}$, Jones RL.. Problems encountered by primary care physicians in the care of patients with diabetes. Arch Fam Med. 1993;2(7):739-741.

27. Bell JS, Enlund $\mathrm{H}$, Vainio K. Medication adherence: a review of pharmacy education, research, practice and policy in Finland. Pharm Pract (Internet). 2010;8(3):147-161.

28. MacLaughlin EJ, Raehl CL, Treadway AK, Sterling TL, Zoller DP, Bond CA. Assessing medication adherence in the elderly; which tools to use in clinical practice? Drugs Aging. 2005;22(3):231-255. 
29. Dunbar-Jacob J, Mortimer-Stephens MK. Treatment adherence in chronic disease. J Clin Epidemiol. 2001;54(Suppl 1):S57-60.

30. Adisa R, Alutundu MB, Fakeye TO. Factors Contributing to Nonadherence to Oral Hypoglycemic Medications among Ambulatory Type 2 Diabetes Patients in Southwestern Nigeria. Pharm Pract (Internet). 2009;7(3):163-169.

31. Krueger KP, Felkey BG, Berger BA. Improving adherence and persistence: a review and assessment of interventions and description of steps towards a national adherence initiative. J Am Pharm Assoc. 2003;43(6):668-678.

32. The Creative Research Systems. The complete survey software solution since 1982. Research Aids. Available at www.surveysystem.com/sscalc.html (Accessed 25 May, 2009).

33. United Kingdom Prospective Diabetes Study (UKPDS) Group. Intensive blood-glucose control with sulphonylureas or insulin compared with conventional treatment and risk of complications in patients with type 2 diabetes (UKPDS 33). Lancet. 1998;352(9131):837-853.

34. United Kingdom Prospective Diabetes Study Group. Effect of intensive blood-glucose control with metformin on complications in overweight patients with type 2 diabetes (UKPDS 34). Lancet. 1998;352(9131):854-865.

35. Morisky DE, Green LW, Levine DM. Concurrent and predictive validity of a self- reported measure of medication adherence. Med Care. 1986;24(1):67-74.

36. World Health Organization. Adherence to long term therapies. Evidence for Action. WHO 2003. Accessed 25 June 2009

37. Vik SA, Maxwell CJ, Hogan DB, Patten SB, Johnson JA, Romonko-Slack L. Assessing medication adherence among older persons in community settings. Can J Clin Pharmacol. 2005;12(1):e152-e164.

38. Cramer J. Identifying and improving compliance patterns. In: Cramer JA, Spilker B, eds. Patient compliance on medical practice and clinical trials. New York: Raven Press, 1991:387-392.

39. Elliott WJ, Maddy R, Toto R, Bakris G. Hypertension in patients with diabetes ; overcoming barriers to effective control. Postgrad Med. 2000 Mar;107(3):29-32, 35-6, 38.

40. Krammer AM. Healthcare for elderly persons-myths and realities. N Engl J Med. 1995;332(15):1027-1029.

41. Osterberg L, Blaschke T. Adherence to medication. N Engl J Med. 2005;353(5):487-497.

42. Beed G. Managing diabetes in a managed care environment: Part II. Managed Care Interface. 1999;12(suppl1):32-35.

43. Turner RC, Cull CA, Frighi V, Holman RR. Glycemic control with diet, sulfonylurea, metformin, or insulin in patients with type 2 diabetes mellitus: progressive requirement for multiple therapies (UKPDS 46). UK Prospective Diabetes Study (UKPDS Group). JAMA. 1999;281(21):2005-2012.

44. Blonde L. Removing polytherapy as a barrier to adherence. Managed Care Interface. 2000;13(special suppl): Introduction

45. Ezenwaka CE, Akanji AO, Akanji BO, Unwin NC, Adejuwon CA. The prevalence of insulin resistance and other cardiovascular disease risk factors in healthy elderly, southwestern Nigerians. Atherosclerosis. 1997;128(2):201-211.

46. Enwere OO, Salako BL \& Falade CO. Prescription and cost consideration at a diabetic clinic in Ibadan, Nigeria: A report. Annals of Ibadan Postgraduate medicine. 2006;4(2):35-39

47. American Diabetes Association. Clinical Practice Recommendations 2000. Diabetes Care. 2000;23(Suppl 1):S1-116.

48. Testa MA, Simonson DC. Health economic benefits and quality of life during improved glycemic control in patient with type 2 diabetes mellitus. JAMA. 1998;280(17):1490-1496.

49. Sczupak CA, Conrad WA. Relationship between patient-oriented pharmaceutical services and therapeutic outcome of ambulatory patients with diabetes mellitus. Am J Hosp Pharm. 1977;34(11):1238-1242.

50. Jayant D, Blonde L, Guthrie R Jr. Factor Influencing patient Acceptability of Diabetes Treatment Regimens. Clinical Diabetes. 2000;18(2):61.

51. American Diabetes Association. Standards of medical care for patients with diabetes mellitus. Diabetes Care. 2004; 27(Suppl1): S15-S35.

52. Haynes RB, Taylor DW, Sackett DL, Gibson ES, Bernholz CD, Mukherjee J. Can simple clinical measurements detect patient compliance? Hypertension. 1980;2(6):757-764.

53. Craig HM. Accuracy of indirect measure of medication compliance in hypertension. Res Nurs Health. 1985;8(1):61-66.

54. Fletcher SW, Pappius EM, Harper SJ. Measurement of medication compliance in a clinical setting. Comparison of three methods in patients prescribed digoxin. Arch Intern Med. 1979;139(6):635-638.

55. Grymonpre RE, Didur CD, Montgomery PR, Sitar DS. Pill count, self report, and pharmacy claims data to measure medication adherence in the elderly. Ann Pharmacother 1998;32(7-8):749-754.

56. Yusuff KB, Obe O, Joseph BY. Adherence to antidiabetic drug therapy and self management practices among type 2 diabetes in Nigeria. Pharm World Sci. 2008;30(6):876-883

57. Adibe MO, Aguwa C N, Ukwe CV,Okonta JM, Udeogaraniya PO. Outpatient utilization of antidiabetic drugs in the South Eastern Nigeria. International Journal of Drug Development \& Research. 2009;1(1):27-36.

58. Botelho RJ, Dudrak R 2nd. Home assessment of adherence to long-term medication in the elderly. J Fam Pract. 1992;35(1):61-65.

59. Roter D. Advancing the physician's contribution to enhancing compliance. J Pharmacoepidemiol. 1995;3(2):37-48.

60. Sleath B, Chewing B, Svardstad B, Roter D. Patient expression of complaints and adherence problems with medications during chronic disease medical visits. J Soc Admin Pharm. 2000;17:71-80.

61. Miller RW, Rollnick S. In Motivational Interviewing: Preparing People to change Addictive Behavior. New York NY: Guilford Press. 1991

62. Chobanian AV, Bakris GL, Black HR, Cushman WC, Green LA, Izzo JL Jr, Jones DW, Materson BJ, Oparil S, Wright JT Jr, Roccella EJ; National Heart, Lung, and Blood Institute Joint National Committee on Prevention, Detection, Evaluation, and Treatment of High Blood Pressure; National High Blood Pressure Education Program Coordinating 
Adisa R, Fakeye TO, Fasanmade A. Medication adherence among ambulatory patients with type 2 diabetes in a tertiary healthcare setting in southwestern Nigeria. Pharmacy Practice (Internet) 2011 Apr-Jun;9(2):72-81.

Committee. National Heart, Lung and Blood Instutitute. Joint National committee on Prevention, Detection, Evaluation and Treatment of High Blood Pressure: The JNC 7 Report. JAMA. 2003;289(19):2560-2572.

63. Coons SJ, Sheahan SL, Martin SS, Hendricks J, Robbins CA, Johnson JA. Predictors of medication noncompliance in a sample of older adults. Clin Ther. 1994;16(1):110-117. 